\title{
Faktor-Faktor Apa Saja Yang Berhubungan Dengan Pencapaian Pelaksanaan Ambulasi Dini Pada Ibu Pascapartum Di Ruang Rawat Inap RSKDIA Siti Fatimah Makassar
}

\author{
Factors Associated With Early Attaiment Implementation Of The Mother Postpartum \\ Ambulation In Inpatient Room RSKDIA Siti Fatimah Makassar
}

\author{
Elfina $^{1}$, Risma Muchtar ${ }^{2}$, Fadly Umar ${ }^{3}$ \\ Akademi Kebidanan Graha Ananda Palu \\ Email :sstelfina800@gmail.com
}

\begin{abstract}
Abstrak
Ibu biasanya khawatir gerakan-gerakan yang di lakukan akan menimbulkan dampak yang tidak di inginkan. Padahal, apabila ibu bersalin melakukan ambulasi dini, itu bisa memperlancar terjadinya proses involusi uteri. Penelitian ini bertujuan untuk mengetahui faktor-faktor yang berhubungan pencapaian pelaksanaan ambulasi dini pada ibu pascapartum. Desain penelitian yang di gunakan dalam penelitian ini adalah "cross sectional study" Sampel dalam penelitian ini berjumlah 35 orang. Sampel diambil dengan teknik non probability sampling yaitu purposive sampling. Variabel independen adalah pengetahuan, bimbingan bidan/perawat, jenis pertolongan persalinan dan dukungan keluarga. Variabel dependen adalah ambulasi dini pasca partum. Instrumen penelitian dengan menggunakan lembar kuesioner dan lembar observasi. Berdasarkan hasil uji Fischer's exact test dengan taraf kesalahan $(\alpha)=0,05$ diperoleh nilai $p=0,006$ untuk pengetahuan, nilai $p=0,000$ untuk bimbingan perawat/bidan, nilai $p=0,001$ untuk jenis pertolongan persalinan dan nilai $p=0,003$ untuk dukungan keluarga. Dengan demikian dapat disimpulkan bahwa Ada hubungan yang signifikan antara pengetahuan, bimbingan perawat/bidan, jenis pertolongan persalinan dan dukungan keluarga dengan pelaksanaan ambulasi dini pasca partum.
\end{abstract}

Kata kunci : Ambulasi dini, pascapartum

\begin{abstract}
The mother usually worried that the movements do will have an impact that does not want. In fact, if the birth mother did early ambulation, it could expedite the process of uterine involution. This study aims to determine the factors related to the attainment implementation of early ambulation in the mother postpartum. The research design used in this study is the "cross-sectional study" The sample in this study amounted to 35 people. Samples were taken by non-probability sampling technique that is purposive sampling. Independent variable is the knowledge, guidance nurses/midwife, type of delivery assistance and family support. The dependent variable is early ambulation post-partum. The research instrument by using a questionnaire sheet and observation sheet. Based on test results of Fischer's exact test with a standard error $(\alpha)=0.05 p=$ 0.006 values obtained for knowledge, the value of $p=0.000$ for the guidance of nurses $/$ midwife, $p=0.001$ for the type of aid delivery and the value $p=0,003$ for family support. Thus we can conclude that there is a significant correlation between knowledge, guidance nurses/midwife, type of delivery assistance and family support with the implementation of early post-partumambulation.
\end{abstract}

Keywords: early ambulation, postpartum 


\section{PENDAHULUAN}

Kehamilan, persalinan dan nifas adalah proses normal dalam siklus seorang ibu, tetapi perubahan-perubahan organ tubuh pada keadaan tertentu, dapat menimbulkan penyulit yang berbahaya untuk ibu atau kehamilan itu sendiri. Sebagai akibat persalinan terjadi kelemahan-kelemahan ligamen dan otot serta dasar panggul sehingga prolaps genetalis sering terjadi segera sesudah melahirkan atau pada masa nifas. Frekuensi prolaps genetalia lebih sering di jumpai pada wanita-wanita yang telah melahirkan, wanita berusia lanjut dan wanita dengan pekerjaan berat. [1].

Umumnya, para ibu pasca melahirkan takut melakukan banyak gerakan. Ibu biasanya khawatir gerakan gerakan yang di lakukan akan menimbulkan dampak yang tidak di inginkan. Padahal, apabila ibu bersalin melakukan ambulasi dini, itu bisa memperlancar terjadinya proses involusi uteri [2].

Glazener et al (1993), menyatakan lebih dari tiga perempat (76 \%) ibu melaporkan gejala yang menetap lebih dari 8 minggu setelah melahirkan, ibu mengeluh nyeri punggung yang tak kunjung mereda, nyeri perineum, kesulitan dalam berhubungan seksual, depresi dan kelelahan luar biasa. Banyak ibu yang berjuang sendiri selama bertahuntahun memerangi masalah kesehatan kronis yang muncul sejak mereka melahirkan, namun tidak pernah mencari bantuan [3].

Dari berbagai laporan yang menyatakan banyaknya komplikasi yang di alami ibu pascapartum di akibatkan oleh kurangnya pergerakan/latihan baik selama hamil dan segera setelah melahirkan, maka di harapkan ibu pascapartum dapat melakukan ambulasi sesegera mungkin, seperti melakukan gerakan kaki, bergeser ketempat tidur, melakukan nafas dalam, teknik bangkit dari tempat tidur [4]. Hal ini merupakan profilaksis terhadap terjadinya prolaps genetalis, dan upaya perbaikan dalam sistem pernapasan dan peningkatan kerja jantung [3].

Kelelahan yang sangat akibat persalinan karena tidak pernah olahraga atau latihan pada masa sebelumnya, sedang dan sesudah hamil merupakan hal yang perlu di perhatikan. Maka bila tidak ada kontra indikasi, bidan dapat membimbing ibu melakukan mobilisasi dan ambulasi untuk meningkatkan kekuatan otot perut, punggung dan dasar panggul sehingga lekas kembali ke keadaan semula [5].

Helen Farrer (1987) juga mengatakan ambulasi dini sangat penting dalam mencegah trombosis vena. Setelah persalinan, jika pergerakan tidak terhalang oleh pemasangan infuse dan kateter serta tanda-tanda vitalnya, ibu diperbolehkan untuk mandi dan pergi ke wc dengan dibantu, dua atau tiga jam setelah persalinan. Sebelum ibu diminta untuk melakukan latihan tungkai yang sederhana dan harus duduk serta menganyunkan tungkai ditepi tempat tidur. Latihan menguatkan otot perut, membentuk tubuh yang baik, mengencankan dasar panggul dan membantu sirkulasi darah seluruh tubuh [5].

Rawannya kesehatan ibu menurut Survey Demogravi Kesehatan Indonesia (2012) ditandai oleh Semakin tingginya angka kematian ibu di Indonesia tahun 2012 yaitu 359 per 100.000 kelahiran hidup. Penyebab utama kematian ibu adalah Perdarahan (28 \%), Eklamsi (24 \%), Infeksi (11\%), Partus Lama (11\%), Abortus (5 \%), dan Lain-Lain (11\%). Sisanya di sebabkan penyakit lainnya yang memburuk resiko kematian ibu seperti umur terlalu muda atau terlalu tua, jumlahnya anak lebih dari 4, jarak kelahiran kurang dari 2 tahun [6].

Kematian ibu merupakan tolak ukur kemampuan pelayanan kesehatan di suatu negara. Penyebab kematian ibu seperti komplikasi kehamilan dan persalinan seperti pendarahan, infeksi, emboli air ketuban, dan anestesi, angka kematian tersebut disebabkan juga oleh pendarahan pasca partus 4 kali lebih banyak dibandingkan pendarahan antepartus, dan salah satu penyebab terpenting terjadinya kematian ibu di dunia yang melibatkan 150.000 kematian dalam satu tahun, yang berkaitan erat dengan persalinan kala III, terutama terjadi di Negara berkembang. [7].

Menurut profil kesehatan Sulawesi Selatan tahun (2008), angka kematian maternal sebanyak 121 orang. Penyebab kematian ibu paling tinggi karena pendarahan pasca partus sebanyak 62 0rang (53,9\%). Dan pada tahun 
2009, angka kematian maternal menurun sebanyak 118 orang dengan penyebabnya adalah pendarahan pasca partus 53 orang (48\%). Namun angka ini belum menunjukkan penurunan yang signifikan [8].

Rumah Sakit Khusus Daerah Ibu dan Anak Siti Fatimah Makassar merupakan satu dari beberapa rumah sakit rujukan kasus-kasus kebidanan. Tahun 2012 jumlah persalinan sebanyak 3102 orang dan dari bulan Januari sampai bulan Desember 2013 sebanyak 3831 orang, rata-rata jumlah persalinan perbulan 369 orang.

Dengan melihat tingginya jumlah kunjungan ibu melahirkan tersebut, maka kebutuhan asuhan kebidanan ibu pascapartum sangat penting mendapatkan perhatian, khususnya pengetahuan tentang mobilisasi maupun ambulasi dini pascapartum.

Adapun tujuan penelitian ini yaitu untuk mengetahui faktor-faktor apa saja yang berhubungan dengan pencapaian pelaksanaan ambulasi dini pada ibu pascapartum di ruang rawat inap Rumah Sakit Khusus Daerah Ibu dan Anak Siti Fatimah Makassar tahun 2014.

\section{METODE}

Desain penelitian yang di gunakan penulis adalah "cross sectional study" di mana peneliti melakukan observasi atau pengukuran variabel pada satu saat tertentu, artinya tiap subyek hanya di observasi satu kali saja dan pengukuran variabel subyek di lakukan pada saat pemeriksaan. [9]. Populasi yang digunakan dalam penelitian adalah 38 orang yaitu semua ibu dengan berbagai jenis tindakan pertolongan persalinan pascapartum di ruang rawat inap Rumah Sakit Khusus Daerah Ibu dan Anak Siti Fatimah Makassar dengan jumlah sampel adalah total dari populasi.

untuk mengetahui hubungan variabel independen dan veriabel dependen dengan menggunakan uji chi-square test dengan menggunakan jasa computer program SPSS versi 16 dan teknik multivariat dengan menggunakan analisis regresi linier untuk melihat hubungan antara satu atau lebih variabel bebas dengan variabel tergantung.

\section{HASIL}

1. Hubungan Pengetahuan dengan Ambulasi Dini pasca partum

Tabel 1. Hubungan Pengetahuan dengan Ambulasi Dini pasca partum di RSKD Ibu dan Anak Siti Fatimah Makassar

\begin{tabular}{|c|c|c|c|c|c|c|c|c|}
\hline \multirow{3}{*}{ Variabel } & \multicolumn{4}{|c|}{ Ambulasi dini pasca partum } & \multirow{2}{*}{\multicolumn{2}{|c|}{ Total }} & \multirow{3}{*}{ P.value } & \multirow{3}{*}{$O R$} \\
\hline & \multicolumn{2}{|c|}{ Baik } & \multicolumn{2}{|c|}{ Kurang } & & & & \\
\hline & $\mathbf{n}$ & $\%$ & $\mathbf{n}$ & $\%$ & $\mathbf{n}$ & $\%$ & & \\
\hline \multicolumn{7}{|l|}{ Pengetahuan } & \multirow{4}{*}{0.006} & \multirow{4}{*}{1.017} \\
\hline Cukup & 22 & 62.9 & 2 & 5,7 & 24 & 68.6 & & \\
\hline Kurang & 5 & 14.3 & 6 & 17,1 & 11 & 31.4 & & \\
\hline Total & 27 & 77.1 & 8 & 22,9 & 35 & 100 & & \\
\hline
\end{tabular}

Sumber : Data Primer, 2016

Hasil analisis bivariat ditemukan bahwa frekuensi responden dengan pengetahuan cukup, yang melakukan ambulasi pasca partum dengan baik sebanyak 22 orang $(62,9 \%)$ dan yang kurang melakukan ambulasi dini pasca partum sebanyak 2 orang (5,7\%). Sedangkan frekuensi responden dengan pengetahuan kurang, yang melakukan ambulasi pasca partum dengan baik sebanyak 5 orang (14,3\%) dan yang kurang melakukan ambulasi dini pasca partum sebanyak 6 orang (17,1\%). Berdasarkan hasil uji Fischer exact test dengan tingkat kemaknaan $\alpha=0,05$ ternyata nilai $\mathrm{p}=0,006$. Karena nilai $\mathrm{p}(0,006)<\alpha(0,05)$ maka Ha diterima dan Ho ditolak. Hal ini menunjukkan bahwa 
ada hubungan antara pengetahuan dengan ambulasi dini pasca partum.

2. Hubungan Bimbingan Bidan/Perawat dengan Ambulasi Dini pasca partum

Tabel 2. Hubungan Bimbingan Bidan/Perawat dengan Ambulasi Dini pasca partum di RSKD Ibu dan Anak Siti Fatimah Makassar

\begin{tabular}{|c|c|c|c|c|c|c|c|c|}
\hline \multirow{3}{*}{ Variabel } & \multicolumn{4}{|c|}{ Ambulasi dini pasca partum } & \multirow{2}{*}{\multicolumn{2}{|c|}{ Total }} & \multirow{3}{*}{ P.value } & \multirow{3}{*}{ OR } \\
\hline & \multicolumn{2}{|c|}{ Baik } & \multicolumn{2}{|c|}{ Kurang } & & & & \\
\hline & $\mathbf{n}$ & $\%$ & $\mathbf{n}$ & $\%$ & $\mathbf{n}$ & $\%$ & & \\
\hline \multicolumn{7}{|l|}{$\begin{array}{l}\text { Bimbingan Bidan / } \\
\text { Perawat }\end{array}$} & \multirow{4}{*}{0.000} & \multirow{4}{*}{3.981} \\
\hline Baik & 27 & 77.1 & 0 & 0 & 27 & 77.1 & & \\
\hline Kurang & 0 & 0 & 8 & 22.9 & 8 & 22.9 & & \\
\hline Total & 27 & 77.1 & 8 & 22,9 & 35 & 100 & & \\
\hline
\end{tabular}

Sumber : Data Primer, 2016

Berdasarkan data ditemukan bahwa frekuensi responden dengan bimbingan Bidan/Perawat baik, semuanya melakukan ambulasi dini pasca partum yaitu sebanyak 27 orang (77,1\%). Sedangkan frekuensi responden dengan bimbingan perawat kurang, semuanya kurang melakukan ambulasi dini pasca partum yaitu sebanyak 8 orang (22,9\%). Berdasarkan hasil uji Fischer exact test dengan tingkat kemaknaan $\alpha=0,05$ ternyata nilai $\mathrm{p}=0,000$. Karena nilai $\mathrm{p}(0,000)<\alpha(0,05)$ maka Ha diterima dan Ho ditolak. Hal ini menunjukkan bahwa ada hubungan antara bimbingan perawat/bidan dengan ambulasi dini pasca partum

3. Hubungan Jenis tindakan pertolongan persalinan dengan Ambulasi Dini pasca partum

Tabel 3. Hubungan Jenis tindakan pertolongan persalinan dengan Ambulasi Dini pasca partum di RSKD Ibu dan Anak Siti Fatimah Makassar

\begin{tabular}{|c|c|c|c|c|c|c|c|c|}
\hline \multirow{3}{*}{ Variabel } & \multicolumn{4}{|c|}{ Ambulasi dini pasca partum } & \multirow{2}{*}{\multicolumn{2}{|c|}{ Total }} & \multirow{3}{*}{ P.value } & \multirow{3}{*}{ OR } \\
\hline & \multicolumn{2}{|c|}{ Baik } & \multicolumn{2}{|c|}{ Kurang } & & & & \\
\hline & $\mathbf{n}$ & $\%$ & $\mathbf{n}$ & $\%$ & $\mathbf{n}$ & $\%$ & & \\
\hline \multicolumn{7}{|c|}{$\begin{array}{l}\text { Jenis tindakan pertolon- } \\
\text { gan persalinan }\end{array}$} & \multirow{4}{*}{0.001} & \multirow{4}{*}{2.769} \\
\hline Normal & 24 & 68.6 & 2 & 5,7 & 26 & 74,3 & & \\
\hline Tidak Normal & 3 & 8.6 & 6 & 17,1 & 9 & 25,7 & & \\
\hline Total & 27 & 77.1 & 8 & 22,9 & 35 & 100 & & \\
\hline
\end{tabular}

Sumber : Data Primer, 2016

Berdasarkan data juga ditemukan bahwa frekuensi responden dengan persalinan normal, yang melakukan ambulasi pasca partum dengan baik sebanyak 24 orang $(68,6 \%)$ dan yang kurang melakukan ambulasi dini pasca partum sebanyak 2 orang (5,7\%). Sedangkan frekuensi responden dengan jenis pertolongan persalinan tidak normal, yang melakukan ambulasi pasca partum dengan baik sebanyak 3 orang $(8,6 \%)$ dan yang kurang melakukan ambulasi dini pasca partum sebanyak 6 orang (17,1\%). Berdasarkan hasil uji Fischer exact test dengan tingkat kemaknaan $\alpha=0,05$ ternyata nilai $\mathrm{p}=0,001$. Karena nilai $\mathrm{p}(0,001)<\alpha(0,05)$ maka Ha diterima dan Ho ditolak. Hal ini menunjukkan bahwa ada hubungan antara jenis pertolongan persalinan dengan ambulasi dini pasca partum. 
4. Hubungan Dukungan keluarga dengan Ambulasi Dini pasca partum

Tabel 4. Hubungan Dukungan keluarga dengan Ambulasi Dini pasca partum di RSKD Ibu dan Anak Siti Fatimah Makassar

\begin{tabular}{|c|c|c|c|c|c|c|c|c|}
\hline \multirow{3}{*}{ Variabel } & \multicolumn{4}{|c|}{ Ambulasi dini pasca partum } & \multirow{2}{*}{\multicolumn{2}{|c|}{ Total }} & \multirow{3}{*}{ P.value } & \multirow{3}{*}{ OR } \\
\hline & \multicolumn{2}{|c|}{ Baik } & \multicolumn{2}{|c|}{ Kurang } & & & & \\
\hline & $\mathbf{n}$ & $\%$ & $\mathbf{n}$ & $\%$ & $\mathbf{n}$ & $\%$ & & \\
\hline \multicolumn{7}{|l|}{ Dukungan Keluarga } & \multirow{4}{*}{0.003} & \multirow{4}{*}{2.300} \\
\hline Baik & 23 & 65,7 & 2 & 5,7 & 25 & 74,3 & & \\
\hline Kurang & 4 & 11,4 & 6 & 17,1 & 10 & 25,7 & & \\
\hline Total & 27 & 77,1 & 8 & 22,9 & 35 & 100 & & \\
\hline
\end{tabular}

Sumber : Data Primer, 2016

Berdasarkan data analisis ditemukan bahwa frekuensi responden dengan dukungan keluarga baik, yang melakukan ambulasi pasca partum dengan baik sebanyak 23 orang $(65,7 \%)$ dan yang kurang melakukan ambulasi dini pasca partum sebanyak 2 orang (5,7\%). Sedangkan frekuensi responden dengan dukungan keluarga kurang, yang melakukan ambulasi pasca partum dengan baik sebanyak 4 orang $(11,4 \%)$ dan yang kurang melakukan ambulasi dini pasca partum sebanyak 6 orang $(17,1 \%)$. Berdasarkan hasil uji Fischer exact test dengan tingkat kemaknaan $\alpha=0,05$ ternyata nilai $p=0,003$. Karena nilai $p(0,003)<\alpha(0,05)$ maka Ha diterima dan Ho ditolak. Hal ini menunjukkan bahwa ada hubungan antara dukungan keluarga dengan ambulasi dini pasca partum.

Analisis multivariat dilakukan dengan cara menghubungkan seluruh variabel independen dan dependen yang bermakna untuk melihat besarnya pengaruh masing-masing variabel setelah dilakukan analisis secara bersama-sama.

Tabel 5. Hubungan Pengetahuan, Bimbingan Bidan/Perawat, Jenis pertolongan persalinan dan Dukungan keluarga dengan Ambulasi Dini pasca partumdi RSKD Ibu dan Anak Siti Fatimah Makassar

\begin{tabular}{lll}
\hline Variabel & OR & Nilai $\mathrm{p}$ \\
\hline Pengetahuan & 1.017 & 0,006 \\
\hline Bimbingan bidan/perawat & 3.981 & 0,000 \\
\hline Jenis pertolongan persalinan & 2.769 & 0,001 \\
\hline Dukungan keluarga & 2.300 & 0,003 \\
\hline
\end{tabular}

Sumber : Data Primer, 2016

Berdasarkan tabel 5. di atas ternyata variabel bebas yang memiliki kekuatan hubungan paling besar dengan ambulasi dini adalah bimbingan bidan/perawat. Hal ini dapat dilihat dari nilai OR (Odds ratio), yaitu: 3.981. Variabel bebas yang memiliki hubungan terbesar kedua adalah jenis pertolongan persalinan dengan nilai OR (Odds ratio) sebesar: 2.769. Variabel bebas yang memiliki hubungan terbesar ketiga adalah dukungan keluarga dengan nilai OR (Odds ratio) sebesar: 2,300. Sedangkan variabel bebas yang memiliki hubungan paling kecil dengan keterampilan ibu adalah pengetahuan dengan nilai OR (Odds ratio) sebesar:1.017.

\section{PEMBAHASAN}

Semakin cukup pengetahuan yang dimiliki tentang ambulasi dini maka pelaksanaan ambulasi dini pasca partum akan semakin baik. Hal ini sependapat dengan Notoatmodjo (2003) bahwa pengetahuan merupakan hasil "tahu" dan terjadi setelah manusia melakukan penginderaan terhadap suatu obyek tertentu, dimana obyek tertentu tersebut berupa informasi-informasi yang penting dan dapat diperoleh darimana saja, baik dari media cetak dan elektronik [10]. Seperti yang telah diungkapkan oleh Notoatmodjo (2003), memahami diartikan sebagai suatu kemampuan menjelaskan secara 
benar tentang obyek yang diketahui dan dapat mengintepretasikan materi tersebut [10]. Ibu post partum yang memiliki pengetahuan yang cukup, dapat disebabkan karena telah memiliki pengalaman sebelumnya tentang pelaksanaan ambulasi dini setelah persalinan atau telah mempelajari atau mempersiapkan diri sebelum persalinannya sehingga apa yang diketahui dapat dilaksanakan pada saat persalinannya.

Pengetahuan atau kognitif merupakan hal yang sangat penting untuk terbentuknya perilaku seseorang dalam hal ini adalah melaksanakan ambulasi dini. Pengetahuan dapat diperoleh melalui pengalaman pribadi atau dari pengalaman orang lain. Begitu halnya yang terjadi pada ibu post partum yang pernah melaksanakan ambulasi dini dengan adanya pengalaman pribadi tersebut dapat digunakan sebagai upaya dalam memperoleh pengetahuan yang baik tentang tahaptahap pelaksanaan ambulasi dini. Walaupun demikian ternyata terdapat responden dengan pengetahuan cukup, tetapi kurang melakukan ambulasi dini pasca partum sebanyak 2 orang (5,7\%).

Bimbingan bidan/perawat memiliki hubungan yang sangat signifikan dalam pelaksanaan ambulasi dini pasca partum. Hal ini dapat dilihat dari frekuensi responden di mana responden dengan bimbingan perawat/bidan baik, semuanya melakukan ambulasi dini pasca partum yaitu sebanyak 27 orang $(77,1 \%)$. Sedangkan frekuensi responden dengan bimbingan perawat/bidan kurang, semuanya kurang melakukan ambulasi dini pasca partum yaitu sebanyak 8 orang (22,9\%). Hal ini sejalan dengan Hidayat (2004) bahwa petugas kesehatan khususnya perawat/bidan sangat berperan penting dalam mempengaruhi perilaku ibu pascasalin. Perawat/bidan merupakan orang yang dalam melakukan tindakannya didasari oleh ilmu pengetahuan serta memiliki keterampilan yang jelas dalam keahliannya. Selain itu perawat/bidan juga mempunyai kewenangan dan tanggung jawab dalam tindakan yang berorientasi pada pelayanan melalui pemberian asuhan keperawatan kepada individu, kelompok dan keluarga. Pemberian asuhan keperawatan ini dapat dilakukan bidan/perawat dengan memperhatikan aspek kebutuhan dasar pasien [11].

Di rumah sakit, bidan/perawat adalah orang yang paling dekat dengan pasien, oleh sebab itu bidan/perawat harus mengetahui kebutuhan pasiennya. Bidan/perawat memberikan asuhan kebidanan pada ibu pasca partum yaitu dengan mengajarkan pada ibu pasca partum bagaimana cara melakukan ambulasi dini yang aman. Awalnya bidan/ perawat dapat membantu ibu dalam melakukan ambulasi dini, kemudian ibu mengulanginya secara rutin dengan bantuan suami atau keluarga selanjutnya ibu akan mampu melakukannya secara mandiri [11]

Jenis pertolongan persalinan memiliki hubungan yang sangat signifikan dalam pelaksanaan ambulasi dini pasca partum. Hal ini dapat dilihat dari frekuensi responden di mana responden dengan persalinan normal, yang melakukan ambulasi pasca partum dengan baik sebanyak 24 orang $(68,6 \%)$. Sebaliknya frekuensi responden dengan jenis pertolongan persalinan tidak normal, yang kurang melakukan ambulasi dini pasca partum sebanyak 6 orang $(17,1 \%)$. Setelah operasi, pada 6 jam pertama ibu paska operasi sectio caesarea harus tirah baring dulu. Ambulasi dini yang bisa di lakukan adalah menggerakkan lengan, tangan, menggerakkan ujung jari kaki dan memutar pergelangan kaki, mengangkat tumit, menegangkan otot betis serta menekuk dan menggeser kaki. Setelah 6-10 jam, ibu di haruskan untuk dapat miring kekiri dan ke kanan untuk mencegah trombosis dan trombo emboli. Setelah 24 jam ibu di anjurkan untuk dapat mulai belajar untuk duduk. Setelah ibu dapat duduk, di anjurkan ibu belajar berjalan.

Menurut Brunner dan Suddarth (2002) bahwa umumnya pasien dengan operasi biasanya mengalami masalah yang sering muncul segera setelah operasi. Pasien telah sadar dan dibawa ke ruang perawatan dengan penurunan kemampuan untuk ambulasi [4]. Hal ini dapat menghambat pelaksanaan ambulasi dini. Masalah yang sering terjadi adalah ketika pasien merasa terlalu nyeri yang membuat mereka tidak ingin melakukan ambilasi dini dan memilih untuk beristirahat di tempat tidur. Sedangkan ibu yang baru menjalani persalinan dengan forsep atau ekstraksi vakum akan mengalami penjahitan dan mungkin memar serta edema. Ibu ini akan ragu-ragu melakukan latihan (khususnya bila mereka pernah mengalami anestesi epidural) dan latihan dasar panggul ringan yang akan membantu penyembuhan 
perineum, latihan ambulasi dini harus diperkenalkan kapanpun ibu siap. Sedangkan responden dengan persalinan normal dapat segera melakukan ambulasi dini.

Responden dengan persalinan normal, yang kurang melakukan ambulasi dini pasca partum sebanyak 2 orang (5,7\%). Hal ini karena kurangnya bimbingan dari perawat. Sedangkan frekuensi responden dengan jenis pertolongan persalinan tidak normal, yang melakukan ambulasi pasca partum dengan baik sebanyak 3 orang (8,6\%). Hal ini disebabkan oleh bimbingan yang baik dari perawat. Ambulasi yang aman memerlukan keseimbangan dan kekuatan yang cukup untuk menopang berat badan dan menjaga postur, beberapa pasien justru sangat memerlukan bantuan dari perawat untuk bergerak dengan aman [12]

Frekuensi responden dengan dukungan keluarga baik, yang melakukan ambulasi pasca partum dengan baik sebanyak 23 orang $(65,7 \%)$. Sebaliknya responden dengan dukungan keluarga kurang, yang kurang melakukan ambulasi dini pasca partum sebanyak 6 orang $(17,1 \%)$. Hal ini menunjukkan bahwa semakin baik dukungan keluarga maka pelaksanaan ambulasi dini pasca partum akan semakin baik. Hal ini sejalan dengan Friedman (1998, dalam Akhmadi 2009) bahwa dukungan keluarga adalah sikap, tindakan dan penerimaan keluarga terhadap penderita yang sakit. Anggota keluarga memandang bahwa orang yang bersifat mendukung selalu siap memberikan pertolongan dan bantuan jika diperlukan. Keluarga meliliki empat fungsi dukungan yaitu: pertama, dukungan informasional. Keluarga berfungsi sebagai sebuah kolektor (pengumpul) dan diseminator (penyebar) informasi. Menjelaskan tentang pemberian saran, sugesti, informasi yang dapat digunakan mengungkapkan suatu masalah.

Manfaat dari dukungan ini adalah dapat menekan munculnya suatu stressor karena informasi yang diberikan dapat menyumbangkan aksi sugesti yang khusus pada individu. Aspek-aspek dalam dukungan ini adalah nasehat, usulan, saran, petunjuk dan pemberian informasi. Dengan demikian keluarga yang mengetahui tentang manfaat ambulasi dini dapat menyampaikan kepada ibu pasca partum untuk melakukannya. Kedua adalah dukungan penilaian. Keluarga bertindak sebagai sebuah bimbingan umpan balik, membimbing dan menengahi pemecahan masalah, sebagai sumber dan validator indentitas anggota keluarga diantaranya memberikan support, penghargaan, perhatian. Ketiga, dukungan instrumental. Keluarga merupakan sebuah sumber pertolongan praktis dan konkrit, diantaranya: kesehatan penderita dalam hal kebutuhan makan dan minum, istirahat, terhindarnya penderita dari kelelahan. Keempat adalah dukungan emosional. Keluarga sebagai tempat yang aman dan damai untuk istirahat dan pemulihan serta membantu penguasaan terhadap emosi. Aspek-aspek dari dukungan emosional meliputi dukungan yang diwujudkan dalam bentuk afeksi, adanya kepercayaan, perhatian, mendengarkan dan didengarkan. Adanya keempat aspek fungsi dukungan keluarga ini sangat membantu pasien pasca partum dalam pelaksanaan ambulasi dini. Dengan adanya dukungan keluarga pasien akan lebih termotivasi untuk melakukan ambulasi dini. Walaupun demikian ternyata terdapat responden dengan dukungan keluarga baik, tetapi kurang melakukan ambulasi dini pasca partum sebanyak 2 orang (5,7\%). Hal ini karena kurangnya bimbingan dari Bidan/perawat.

Setelah dilakukan analisis regresi logistik untuk melihat kekuatan hubungan antara variabel independen dan dependen ternyata variabel bebas yang memiliki kekuatan hubungan paling besar dengan ambulasi dini adalah bimbingan bidan/perawat. Hal ini dapat dilihat dari nilai OR (Odds ratio), yaitu: 3.981. Variabel bebas yang memiliki hubungan terbesar kedua adalah jenis pertolongan persalinan dengan nilai OR (Odds ratio) sebesar: 2.769. Variabel bebas yang memiliki hubungan terbesar ketiga adalah dukungan keluarga dengan nilai OR (Odds ratio) sebesar: 2,300. Sedangkan variabel bebas yang memiliki hubungan paling kecil dengan keterampilan ibu adalah pengetahuan dengan nilai OR (Odds ratio) sebesar : 1.017. Hal ini sesuai dengan Hidayat (2004) bahwa di rumah sakit, bidan/perawat adalah orang yang paling dekat dengan pasien. Bidan/perawat memberikan asuhan keperawatan pada ibu pasca partum yaitu dengan mengajarkan pada ibu pasca partum bagaimana cara melakukan ambulasi dini yang aman. Awalnya bidan/ 
perawat dapat membantu ibu dalam melakukan ambulasi dini, kemudian ibu mengulanginya secara rutin dengan bantuan suami atau keluarga selanjutnya ibu akan mampu melakukannya secara mandiri [11].

\section{KESIMPULAN DAN SARAN}

Berdasarkan penelitian yang telah dilakukan maka dapat disimpulkan bahwa ada hubungan antara pengetahuan dengan faktor-fakor apa saja yang berhubungan dengan pencapaian pelaksanaan ambulasi dini pada ibu pasca partum di Rumah Sakit khusus daerah Ibu dan Anak Siti Fatimah Makassar terdapat hubungan antara bimbingan bidan/perawat dengan faktor-faktor apa saja yang berhubungan dengan pelaksanaan ambulasi dini pada ibu pasca partum di Rumah Sakit Khusus Daerah Ibu dan Anak Siti Fatimah Makassar, terdapat hubungan antara jenis pertolongan persalinan dengan faktor-faktor apa saja yang berhubungan dengan pelaksanaan ambulasi dini pada ibu pasca partum di Rumah Sakit Khusus Daerah Ibu dan Anak Siti Fatimah Makassar dan terdapat hubungan antara dukungan keluarga dengan faktor-faktor apa saja yang berhubungan dengan pelaksanaan ambulasi dini pada ibu pasca partum di Rumah Sakit Ibu dan Anak Khusus Daerah Siti Fatimah Makassar.

Adapun saran dari penelitian ini adalah dengan adanya penelitian ini diharapkan agar semakin meningkatkan motivasi para peneliti untuk melakukan penelitian tentang ambulasi dini khususnya pada ibu pascapartum dengan menggunakan variabel yang belum digunakan oleh penelti, Sebagai bahan acuan dalam meningkatkan pelayanan tentang pelaksanaan ambulasi dini pascapartum sehingga dapat mengurangi komplikasi pascapartum baik pada persalinan normal maupun persalinan dengan tindakan/bantuan alat. Dengan minimnya angka komplikasi pascapartum akan semakin meningkatkan citra rumah sakit dan bagi peneliti selanjutnya yang akan mengambil judul yang sama, dianjurkan mengambil metode penelitian dan variabel yang berbeda untuk menambah wawasan dan memperkaya pendidikan.

\section{DAFTAR PUSTAKA}

[1] Tanton, “Prolaps Genetalis,” 2010. [Online]. Available: lusa.web.id. [Accessed: 14-Mar-2014].

[2] Salamah Ummu Hamnah, "Senam Nifas," 2008. [Online]. Available: akhwat.web.id. [Accessed: 14-Mar-2014].

[3] Askepasbid, "Deteksi Dini Pada Masa Nifas," 2009. [Online]. Available: askepasbid.wordpress.com. [Accessed: 14Mar-2014].

[4] Brunner dan Suddarth, Buku Ajar Keperawatan Medikal Bedah, 8th ed. Jakarta: EGC, 2002.

[5] Ratihrochmat, “Kebutuhan Dasar Ibu Nifas,” 2009. [Online]. Available: ratihrochmat.wordpress.com. [Accessed: 14-Mar-2014].

[6] Depkes R. I., "KepMenKes RI Nomor 796/Menkes/SKVIII/2012. Tentang Pedoman Teknis Pengendalian Kanker Payudara dan Kanker Leher Rahim," 2012. [Online]. Available: hukor.depkes.go.id.

[7] B. Eileen, Senam Hamil \& Nifas-Pedoman Praktis Bidan. Jakarta: EGC, 2007.

[8] D. K. S. Selatan, "Profil kesehatan Sulawesi Selatan 2008," Diperoleh dari http//dinkes-sulsel. go. id/new/images/ pdf/profil/profil\% 20kesehatan\% 20sulsel, vol. 20, no. 2008, p. 20, 2009.

[9] Sastro Asmoro Sudigdo, Ismail Sofyan, Dasar-Dasar Metodologi Penelitian Klinis. Jakarta: Binarupa Aksara, 1995.

[10] S. Notoatmodjo, Pengantar Pendidikan Kesehatan dan Ilmu Perilaku Kesehatan. Yogyakarta: Andi of Set, 2003.

[11] Hidayat, "Faktor yang Berhubungan dengan Kemandirian Pelaksanaan Ambilasi Dini.," 2004.

[12] N. . Yanti, "Faktor yang Mempengaruhi Pelaksanaan Ambulasi Dini," 2010. 